\title{
Implications of a discard ban in multispecies quota fisheries
}

\author{
Aaron Hatcher \\ Portsmouth Business School \\ University of Portsmouth \\ Portsmouth PO1 3DE, United Kingdom
}

\section{Introduction}

Catch discarding, i.e., the throwing back overboard of unwanted fish, is a feature of most, if not all, marine capture fisheries. While discarding represents rational behaviour by fishermen, in response to physical constraints such as hold capacity or management constraints such as quotas, it is a non-trivial problem for fishery managers since subsequent survival rates for fish are generally very low (e.g., Alverson et al. 1994). As well as being economically wasteful, discarding therefore means that rates of fishing mortality will exceed those indicated by observed levels of fish landings, making the achievement of conservation targets difficult.

Although not a new problem, discarding has acquired significant public prominence in recent years. In Europe, for example, discards have become symbolic of a perceived failure of the European Union's Common Fisheries Policy (CFP) to achieve sustainable management of European fish stocks. In its last Green Paper on the future of the CFP 
(CEC 2009), the European Commission identified discards as a major problem and the European Commissioner for Maritime Affairs and Fisheries has recently announced the intention to introduce an EU-wide ban on discards from 2014. At the same time, it is apparent that quotas, which (as currently applied) create incentives to discard, will remain the cornerstone of conservation policy within the EU for the foreseeable future.

What is unclear, however, is exactly how economic incentives in the fishery can be adjusted so that behaviour which is entirely rational can be prevented or avoided. In particular, unless fishing can be (costlessly) selective, making discarding more costly than retaining fish on board raises questions about the design of a multispecies quota system and the ability to enforce quotas at the landing site (the usual point of control). Although quotarelated discarding is not yet illegal in Europe (as it is in Norway) there have been trials in the UK and Denmark of schemes to encourage a "voluntary" discard ban (backed up by on-board camera monitoring) in return for increased quota allowances - so-called "catch quota" schemes. While these trial schemes have been reported as being successful in reducing discards (e.g., MMO 2012), it is uncertain whether such a system can be extended to an entire EU fleet which already experiences quota compliance problems.

A number of studies have examined and characterised the incentives for fishermen to discard at sea rather than to retain and land a part of the catch in response to both management and technological constraints (Anderson 1994, Arnason 1994, Vestergaard 1996, Hatcher 2005b). In essence, discarding is rational wherever the (opportunity) cost of retaining and landing fish exceeds its market value (for a review, see Pascoe 1997). Other studies have focused more generally on the relationship between the harvest technology 
and the feasibility of harvest policies implemented by a regulator (Turner 1997, Herrera 2005, Singh and Weninger 2009, Holland 2010). A notable omission from previous studies has been a consideration of the costs to fishermen (in the form of expected penalties) of non-compliance with management targets, including both quotas and the regulation of discards. This observation can be extended to the relatively small number of studies which have addressed the determination of quota prices in multispecies ITQ fisheries (e.g., Vestergaard 1999, Dupont et al. 2005, Newell, Sanchirico and Kerr 2005, Singh and Weninger 2009, Holland 2010). Since compliance with quotas must be assured through a system of monitoring and enforcement, there is an inevitable relationship between the quota price and the expected penalty for non-compliance with quotas (Chavez and Salgado 2005, Hatcher 2005a). Given that quota compliance is normally monitored at the point of landing, however, this relationship also needs to encompass any costs associated with discarding at sea.

The present paper aims to extend our understanding of discard behaviour and quota markets in multispecies quota-managed fisheries by explicitly considering the costs of non-compliance with both quotas and discard bans as well as the costs of selective fishing (or avoidance). We give particular consideration to a situation in which one or more TACs becomes binding (or "restrictive") at a lower level of individual and aggregate effort than do the other TACs, resulting (at the vessel level) in individual quotas which are restrictive or, in the case of ITQs, supply inelastic. Species for which quotas are thus restrictive in a fishery are often referred to as "choke" species.

In the paper we focus on the incentives for legal and illegal firm behaviour in relation to 
quotas and discard controls in a multispecies fishery and the resulting implications for quota markets. In order to do so we confine our attention to a static model of industry profit maximisation, implicitly taking stock sizes as fixed. We do not consider the broader issues of the growth and predator-prey interactions between species in a dynamic setting. While these issues are important, our interest is in fishermen's behaviour in relation to the management targets and instruments actually chosen by regulators, rather than the determination of optimal (first-best) policies for the fishery. ${ }^{1}$ Our focus on the static incentive structure of regulation nevertheless enables significant insight into the problems facing managers of multispecies fisheries.

We begin by setting up a simple deterministic model of a multispecies, quota-regulated, fishery in which we assume that both over-quota landings and discards can be deterred by means of a unit penalty imposed by the regulator. The basic fishing technology is assumed to be joint in inputs (see, for example, Vestergaard 1999). More strictly, in the absence of additional inputs committed to avoidance or selective fishing, species are caught in fixed proportions depending upon their relative abundance on the fishing grounds, which we assume is constant. With the addition of costly avoidance inputs, the yields of one or more species can be reduced and the technology is then characterised by "weak output disposability" (Turner 1997, Singh and Weninger 2009). We go on to examine the impact of a discard ban on vessels' profit maximising behaviour, in particular where species quotas are not set in proportion to the availability of species on the fishing grounds, considering firstly non-tradeable quotas and then a fishery managed using a tradeable 1 In taking this approach we follow a number of previous studies, including Anderson (1994), Arnason (1994),
Vestergaard (1996), Hatcher (2005b) and Abbott and Wilen (2009). 
quota (ITQ) system. We proceed to show the necessary interdependence between the (expected) penalty rates for discards and for over-quota landings in determining vessel behaviour and hence quota market outcomes. Under an effective discard ban, for example, we expect the quota price for choke species to be bid up to the level of the expected penalty for illegal (over-quota) landings. A final section concludes.

\section{Model and analysis}

\subsection{Basic firm model}

We model a fishery in which an assemblage of $n$ species of fish are caught together by a large number of competitive fishing firms, each operating a single vessel. In a given period, a representative fishing vessel's catch $q_{i}$ of species $i$ is given by $q_{i}(e, a)$, where $e$ is fishing "effort" (a technologically efficient vector of variable inputs) and $a$ represents additional inputs required in order to reduce the yield of certain species, i.e., to fish selectively. We assume the harvest technology is such that

$$
q_{i e}>0, \quad q_{i e e} \leq 0, \quad q_{i a} \leq 0, \quad q_{i e a} \leq 0, \quad i=1,2, \ldots, n
$$

with the last two derivatives strictly negative for at least one species. Thus, fishing selectively (or "avoidance") with $a>0$ implies that total and marginal yields of at least one (but clearly not all) species are reduced. Otherwise, it is implicitly the case that the species are caught in fixed proportions (according to their relative abundance on the fishing grounds). Variable harvesting costs are given by $c(e, a)$, with, we assume,

$$
c_{e}, c_{e e}>0, \quad c_{a}, c_{a a}>0, \quad c_{e a}=c_{a e}=0
$$


We allow for the possibility of a tradeable quota (ITQ) regime under which, at market equilibrium, individual vessel quotas $Q_{i}$ for the $i$ th species are traded at lease prices $r_{i}{ }^{2}$ Otherwise, individual quotas are non-tradeable (INTQs, or simply IQs). Compliance with quotas is enforced at the point of landing, with over-quota landings of species $i$ attracting an expected unit cost (penalty) $\psi_{i}>0 .{ }^{3}$ We make the additional, not unreasonable, assumption that $\psi_{i}$ is greater than the first-sale price for the fish. With discards $d_{i}$, landings of species $i$ are given by $q_{i}(\cdot)-d_{i}$ and non-compliance is therefore defined as $q_{i}()-.d_{i}>Q_{i}$. Fish discarded at sea prior to landing incur an expected unit cost $\omega_{i} \geq 0$, depending upon the implementation (and effectiveness) of a discard ban. ${ }^{4}$

With first-sale prices $p_{i},{ }^{5}$ the vessel operator's short run (expected) profit maximisation problem is ${ }^{6}$

$$
\begin{aligned}
\max _{e, a, d, Q} & \sum_{i} p_{i}\left[q_{i}(e, a)-d_{i}\right]-c(e, a)-\sum_{i} r_{i} Q_{i} \\
& -\sum_{i} \psi_{i}\left[q_{i}(e, a)-d_{i}-Q_{i}\right]-\sum_{i} \omega_{i} d_{i} .
\end{aligned}
$$

2 In the case of an ITQ system, we assume that the vessel is also representative of aggregate effort in the fishery, so that the vessel's quota demands at market equilibrium mirror inverse quota demands in the fishery as a whole (see Singh and Weninger 2009, Hatcher 2012).

3 The expected penalty rate is simply the product of the penalty rate set by the regulator and the firm's subjective probability of incurring the penalty (i.e., the risk of detection and sanction).

4 The assumption of constant expected marginal penalties is perhaps unrealistic, but is convenient for a simple illustration of the relevance of costs for illegal behaviour in determining quota market outcomes. For a discussion of non-linear penalty functions, see Hatcher (2005a).

5 We assume that the species index $i$ completely describes the heterogeneity in the catch. Thus we abstract from any variation in prices within species.

6 For simplicity, we assume that vessels have a zero quota endowment at the beginning of each period. For a competitive firm this makes no difference to the marginal conditions and hence has no impact on the results. This would not be the case if we were to consider the exercise of market power in the quota market (see Hatcher 2012). 
The first order conditions for $e^{*}, a^{*}, d_{i}^{*}, Q_{i}^{*}>0$ are then respectively

$$
\begin{gathered}
\sum_{i}\left[p_{i}-\psi_{i}\right] q_{i e}=c_{e}>0, \\
\sum_{i}\left[p_{i}-\psi_{i}\right] q_{i a}=c_{a}>0, \\
\psi_{i}-p_{i}=\omega_{i}, \quad i=1,2, \ldots, n, \\
r_{i}=\psi_{i}, \quad i=1,2, \ldots, n .
\end{gathered}
$$

Note that in $(2 \mathrm{a})$ we must have at least one of the terms $\left[p_{i}-\psi_{i}\right] q_{i e}$ strictly positive for vessel activity $\left(e^{*}>0\right)$. In $(2 \mathrm{~b})$ we have a similar requirement for a positive level of avoidance effort $a^{*}$, which requires that $\psi_{i}>p_{i}$ where $q_{i a}<0$. From $(2 \mathrm{c})$ it is apparent that banning discards requires that $\psi_{i}-p_{i}<\omega_{i}$ always holds as an inequality, i.e., the marginal cost of discarding $\left(\omega_{i}\right)$ must always exceed the cost of landing $\left(\psi_{i}-p_{i}\right)$. If $\omega_{i}=0$, then the discard condition is given by $\psi_{i}-p_{i}=0$, which means that any species of fish with a positive expected cost of landing will be discarded at sea. If quotas are tradeable, we can see from $(2 \mathrm{~d})$ that the $\psi_{i}$ (the unit penalties for landing fish without quota) will form ceilings on quota prices. If quotas are not tradeable, then the $Q_{i}$ are no longer choice variables and the final set of first order conditions disappear accordingly.

\subsection{Non-tradeable individual catch quotas}

\section{IQs with a discard ban}

If a non-tradeable quota is exceeded at the point of control, i.e., if for species $i$ we have $q_{i}(\cdot)-d_{i}>Q_{i}$, then by assumption the associated $\psi_{i}$ is positive. If we have an effective discard ban, implying that the $\omega_{i}$ are of sufficient magnitude to ensure that $d_{i}^{*}=0, \forall i$, 
then there are just two possible profit-maximising outcomes. One is where condition (2b) does not hold, which implies that selective fishing is not profitable and hence $a^{*}=0$. Either fish are landed over-quota, with a penalty incurred, or effort is not expanded beyond the point at which the quota is filled: this will depend upon the magnitude of $\psi_{i}$. The other possible outcome is where $(2 \mathrm{~b})$ does hold, which implies that it is profitable to fish selectively $\left(a^{*}>0\right)$, reducing the yield of the species for which the quota is restrictive. Again, by restrictive we mean that, if fishing is non-selective, this quota binds at a lower level of fishing effort $e$ than do the other quotas. This implies that quotas are not set in proportion to the relative availability of species on the fishing ground (otherwise, all quotas would bind at the same level of - non-selective - effort).

Assume, for example, that in a two-species fishery $(i=1,2)$ the quota for species 1 is restrictive in this sense and let the value of $\omega_{1}$ be arbitrarily large, so that there is no discarding. From (2a) and (2c), the optimal level of effort $e^{*}$ solves

$$
\omega_{1}>\psi_{1}-p_{1}=\frac{1}{q_{1 e}}\left[p_{2} q_{2 e}-c_{e}\right]>0 .
$$

The LHS of the equality in (3) is the marginal cost of landing fish of species 1 illegally (i.e., over-quota), while the RHS of the equality is the marginal cost of reducing the catch of species 1 by reducing fishing effort, including the associated loss in the value of catches of species 2 (for which the vessel still has quota). We can re-write the equality in (3) as

$$
p_{1} q_{1 e}+p_{2} q_{2 e}-c_{e}=\psi_{1} q_{1 e}>0
$$

to see that effort is effectively constrained by the quota for species 1 (depending upon the value of $\left.\psi_{1}\right)$. 
From $(2 \mathrm{~b})$ and $(2 \mathrm{c})$, we obtain the condition for $a^{*}>0$ as

$$
\omega_{1}>\psi_{1}-p_{1}=-\frac{c_{a}}{q_{1 a}}+p_{2} \frac{q_{2 a}}{q_{1 a}}>0
$$

Again, the LHS of the equality in (5) is the marginal cost of landing fish of species 1 illegally. The first term on the RHS of the equality is the marginal cost of reducing the catch of species 1 by fishing selectively. If $q_{1 a}<0$, then this is positive. The second term on the RHS of the equality is the associated marginal loss in revenue from a change in the yield of species 2. Assuming that $q_{1 a}<0$, this is positive if $q_{2 a}<0$. If $q_{2 a}=0$ (selectivity has no impact on the yield of species 2) then (5) reduces to

$$
\omega_{1}>\psi_{1}-p_{1}=-\frac{c_{a}}{q_{1 a}}>0 .
$$

In this case, the optimal levels of fishing effort and avoidance jointly solve

$$
p_{2} q_{2 e}=c_{e}-c_{a} \frac{q_{1 e}}{q_{1 a}}>0
$$

(note that this does not imply that the catch of species 1 is reduced to zero). Equation

(7) equates the marginal revenue from species 2 with the marginal cost of effort and the cost of avoidance for the marginal yield of species 1 .

\section{IQs with discarding}

If, in our two species example, $\omega_{1}=0$, then provided $\psi_{1}-p_{1}>0$ the optimal level of effort simply solves

$$
p_{2} q_{2 e}=c_{e},
$$

where the marginal catch of species 1 is discarded entirely once the quota is filled. The optimality condition for avoidance becomes

$$
p_{2} q_{2 a}=c_{a} \geq 0
$$


If $q_{2 a} \leq 0$, this implies that $a^{*}=0$ : there is no incentive to fish selectively when discarding is costless. ${ }^{7}$

If the expected discarding cost $\omega_{1}$ is positive, but is nevertheless smaller than the expected cost of landing over quota, i.e., if we have $0<\omega_{1}<\psi_{1}-p_{1}$, then optimal effort solves

$$
p_{2} q_{2 e}-c_{e}=\omega_{1} q_{1 e}>0
$$

Here, all over-quota fish of species 1 are again discarded rather than landed, but effort is now constrained by the (expected) cost of discarding. If avoidance is profit-maximising, then assuming $q_{2 a}=0$ the optimal levels of fishing effort and avoidance jointly solve (7) as before.

\subsection{Tradeable catch quotas (ITQs)}

\section{ITQs with a discard ban}

Under an ITQ system, quota prices cannot exceed $\psi_{i}$, the expected penalty for landing fish without quota. For a discard ban to be effective, it must always be more costly to discard than it is to land fish (with or without quota). Thus, we require (expected) penalty rates $\omega_{i}$ and $\psi_{i}$ such that

$$
\omega_{i}>\psi_{i}-p_{i} \geq r_{i}-p_{i}
$$

7 If we had $q_{2 a}>0$, i.e., if selective fishing increased the (absolute) yield of species 2, then selective effort would of course be profitable even though over-quota fish of species 1 can be costlessly discarded. If this were the case, however, we might presume that the additional inputs would become part of the "normal" profit maximising vector of fishing effort inputs $e^{*}$. 
and hence

$$
\psi_{i} \geq r_{i}
$$

If $r_{i}=\psi_{i}$, the vessel will be indifferent between landing fish legally and illegally, although we assume (as is conventional) that in this case the vessel will land legally if it is possible to do so, i.e., to purchase quota at this price. Given this, a vessel's optimal level of fishing effort is where

$$
\sum_{i}\left[p_{i}-r_{i}\right] q_{i e}=c_{e} \geq 0
$$

in which, for a non-trivial solution $\left(e^{*}>0\right.$ and hence $\left.c_{e}>0\right)$, we must have at least one of the terms $\left[p_{i}-r_{i}\right] q_{i e}$ strictly positive.

With two species, we can write the first order condition for effort as

$$
\left[p_{1}-\tilde{r}_{1}\right] q_{1 e}+\left[p_{2}-\tilde{r}_{2}\right] q_{2 e}=c_{e}>0
$$

where it is implicitly assumed that the market for both quotas just clears at the same level of effort. We denote the corresponding equilibrium quota prices $0<\tilde{r}_{i}<p_{i}, \forall i$. Consider, though, what will happen if the supply of species 1 quota becomes inelastic to vessels at a lower level of effort than is the case for species 2 quota (this is equivalent to saying that the $T A C$ for species 1 is restrictive, in the sense introduced in the previous section, for the industry as a whole). If the value of $\psi_{1}$ is sufficiently low that it is nevertheless profitable for vessels to expand effort further to clear the market for species 2 quota, landing species 1 fish without quota if necessary, then vessels will be willing to pay up to $\psi_{1}$ for species 1 quota and will be indifferent between holding quota and paying the penalty for landing over-quota fish of species $1 .^{8}$ With $r_{1}$ thus bid up to equal $\psi_{1}$, at the optimal level of

8 This will not be the case for all specifications of the expected penalty function, however. For a discussion of the significance of penalties for relative violations in particular, see Hatcher (2005a, 2012). 
effort we will then have

$$
\left[p_{1}-\psi_{1}\right] q_{1 e}+\left[p_{2}-\hat{r}_{2}\right] q_{2 e}=c_{e}
$$

where the first term on the LHS is now negative. Assuming for the moment that $a^{*}=0$, for each vessel (and in aggregate), then there is a unique level of fishing effort $e$ that will just clear the market for species 2 quota, and from (14) and (15), since we have the same value of $c_{e}$, we must then have $\hat{r}_{2}<\tilde{r}_{2}$. All else equal, therefore, the effect of the restrictive quota on species 1 is to reduce the equilibrium quota price for species 2 . The reason for this is simply that the value of the marginal catch of species 2 is reduced, reflecting the fact that it is now more costly to land the associated marginal catch of species 1 .

If, on the other hand, the expected penalty rate $\psi_{1}$ is high enough to prevent effort expanding further once the quota supply for species 1 becomes inelastic, then there will be excess supply of species 2 quota, with the result that the equilibrium quota price for species 2 is zero. A vessel's optimal level of effort then solves

$$
\left[p_{1}-r_{1}\right] q_{1 e}+p_{2} q_{2 e}=c_{e}
$$

since we assume that, for any greater level of effort (increasing the catch of species 1) we will have $\left[p_{1}-\psi_{1}\right] q_{1 e}+p_{2} q_{2 e}<c_{e}$ (note the implicit discontinuity in the marginal benefit function).

In our two-species example, the condition for positive avoidance effort with respect to species 1 is

$$
\omega_{1}>\psi_{1}-p_{1} \geq r_{1}-p_{1}=-\frac{c_{a}}{q_{1 a}}-\left[r_{2}-p_{2}\right] \frac{q_{2 a}}{q_{1 a}},
$$

where the LHS of the equality is the cost of landing fish of species 1. To simplify things, 
let $q_{2 a}=0$ as before, so that (17) reduces to

$$
\omega_{1}>\psi_{1}-p_{1} \geq r_{1}-p_{1}=-\frac{c_{a}}{q_{1 a}}>0
$$

Assuming that $q_{1 a}<0$, selective fishing only becomes a rational choice if $r_{1}>p_{1}$. Otherwise, it is optimal to fish non-selectively and (assuming a discard ban is effective) to land all the catch. If selective fishing is profit-maximising, then from (14) and (18), optimal effort and avoidance then jointly solve

$$
\left[p_{2}-r_{2}\right] q_{2 e}=c_{e}-\left[p_{1}-r_{1}\right] q_{1 e}=c_{e}-c_{a} \frac{q_{1 e}}{q_{1 a}}>0
$$

which, notice, is formally similar to (7). Given $q_{2 a}=0$, we can continue to assume that the market for species 2 quota clears at the same level of (aggregate) effort, and since (15) continues to hold, this again implies that the quota price for species 2 is reduced due to the restrictive TAC on species 1. Differentiating through (15) by a and rearranging, however, we obtain

$$
\frac{\partial r_{2}}{\partial a}=\left[p_{1}-\psi_{1}\right] \frac{q_{1 e a}}{q_{2 e}}>0
$$

which uses $c_{e a}=q_{2 e a}=0$ and is signed given $p_{1}<\psi_{1}$ (as we have assumed) and $q_{1 e a}<0$. All else equal, therefore, avoidance effort on species 1 increases the species 2 quota price.

\section{ITQs with discarding}

With $\omega_{1}=0$, from $(2 \mathrm{c})$ and $(2 \mathrm{~d})$ the discard condition for species 1 is $r_{1}=p_{1}$. It is apparent, however, that with costless discarding the equilibrium quota price for species 1 can never rise above $p_{1}$, since there is no demand for quota at a price where the revenue from landing fish falls below zero. Given (17), therefore, selective effort cannot be profit maximising if discarding is costless. 
If, however, we have $0<\omega_{1}<\psi_{1}-p_{1}$, then the quota price ceiling for species 1 becomes $\omega_{1}+p_{1}<\psi_{1}$. In this case a positive level of selective fishing effort is clearly profitmaximising (depending upon the marginal cost of avoidance).

\subsection{Note: discards counted against quotas}

If discards are permitted, but their volume (by species) can be monitored and counted against a vessel's quota holdings, then the $d_{i}$ arguments disappear from the quota penalty function in (1) and we have $\omega_{i}=0$. The first order conditions for $d_{i}^{*}>0$ then change to simply

$$
p_{i}=0, \quad i=1,2, \ldots, n \text {. }
$$

Given this (rather strong) assumption, under either IQs or ITQs vessels have no incentive to discard any fish having a positive market price. The results are then exactly the same as in the case of an effective discard ban.

\section{Summary and conclusion}

We have examined the implications of a discard ban in a multispecies quota fishery, in particular the effects on firms' profit-maximising behaviour and on equilibrium quota prices under an ITQ system. The focus has been on discarding in response to inelastic quota supply for so-called "choke" species, arising from a discrepancy between the proportions in which TACs are imposed for different species and their relative abundance on the fishing grounds. We have shown that quota market outcomes depend crucially upon the relative costs of discarding and over-quota landings. It is simply not possible 
to model the formation of quota prices in an ITQ fishery without explicitly considering firm behaviour in relation to the quota compliance policies implemented by regulators: equilibrium quota prices are sensitive to the expected marginal penalties for both discards and illegal landings as well as to input and output prices.

We have seen that, in the case of non-tradeable quotas (such as individual vessel quotas), an effective discard ban, if it can be imposed, results either in the "choke" species being landed illegally, or in the effective constraint of fishing effort to the point at which the TAC for the choke species binds upon the industry. Which outcome prevails then depends upon the magnitude of the (expected) penalty rate for over-quota landings. A successful discard ban implies a (prohibitively large) expected cost for discarding over-quota fish and, depending upon the size of expected penalties for illegal landings, this will create incentives for selective fishing (avoidance). If discarding is costless, on the other hand, all choke species will simply be discarded once the corresponding TAC binds: there is no constraint on fishing effort and no incentive for costly avoidance. An expected discarding cost that is positive, but less than the expected cost for illegal landing, can create incentives for avoidance effort but will not eliminate discards of the choke species.

Under an ITQ system, when a choke species TAC becomes binding upon the industry the supply of quota becomes inelastic to the individual vessel. With a discard ban, the corresponding quota price will be bid up to the level of the expected penalty for illegal landings, at which point vessels are indifferent between landing legally and illegally. ${ }^{9}$ If the expected penalty for illegal landings is high enough, fishing effort is constrained to

${ }^{9}$ Holland (2010) notes that this quota price inflation may not be observed in practice, for example in the case of 
where the choke species TAC just binds. Otherwise, inflation of the quota price for the choke species (up to the level of the expected penalty for over-quota landings) results in lower equilibrium quota prices for other species. Under ITQs, selective fishing only becomes profitable (depending on the marginal costs of avoidance) once the quota price exceeds the dockside (landing) price. Avoidance effort reduces the costs to the vessel from catching the choke species and so increases economic profits and hence the quota price for other species.

With costless discarding, the quota price for the choke species can never rise above the dockside price and the additional cost of selective fishing effort is never profitable. A positive but small (expected) discarding cost (less than the expected cost of illegal landing), on the other hand, inflates the quota price for the choke species above the market price and makes avoidance effort potentially profitable.

The imposition of a discard ban appears to be a logical and uncontroversial step in reducing economic waste in a multispecies quota fishery. Even assuming that it is technologically feasible to monitor all discards, however, so that vessels can expect to incur a significant cost if they discard, the implications may not be straightforward. Specifically, the alternatives to discarding are either an increase in illegal (i.e., over-quota) landings, or more selective fishing, or the constraint of fishing effort to the level at which the most restrictive TAC (the choke species) becomes binding on the industry. As we have seen, which outcome predominates depends upon the expected costs and benefits of each al-

choke species in the B.C. groundfish trawl fishery. At the fishery level the explanation is reported as an agreement amongst participants not to engage in "gouging" (charging very high prices for scarce quota). An alternative explanation would be that the expected penalties for landing choke species without quota are not, in reality, very high. 
ternative, and in particular, the marginal costs of landing over-quota fish and of avoiding catches of the choke species. Whether or not a discard ban is potentially welfare improving in any given situation, therefore, will depend on a number of complex factors, of which the regulatory cost of imposing such a ban is but one.

Finally, looking at the problem of "quota-induced" discarding of choke species from the regulator's perspective, an heuristic approach to reducing the volume of discards would be to set TACs in proportions closer to the average observed ratios of species in the harvest. This raises questions relating to the scientific and political rationale and processes around setting TACs in multispecies (and often multi-national) fisheries which lie beyond the scope of the paper. There may be trade-offs, for example, between setting a first-best TAC for a particular species and setting a different TAC which leads to lower rates of discards and/or illegal landings in the fishery.

\section{References}

Abbott, J. K., and J. E. Wilen (2009) Regulation of fisheries bycatch with common-pool output quotas. Journal of Environmental Economics and Management, 57: 195-204.

Alverson, D. L., M. H. Freeberg, S. A. Murawski and J. G. Pope (1994). A global assessment of fisheries bycatch and discards. FAO Fisheries Technical Paper, 339. Rome: FAO.

Anderson, L. G. (1994). An economic analysis of highgrading in ITQ fisheries regulation 
programs. Marine Resource Economics, 9: 209-226.

Arnason, R. (1994). On catch discarding in fisheries. Marine Resource Economics, 9: $189-207$.

CEC (Commission of the European Communities) (2009) Green Paper: Reform of the Common Fisheries Policy. $\mathrm{COM}(2009) 163$ final. Brussels: CEC.

Dupont, D. P., K. J. Fox, D. V. Gordon and R. Q. Grafton (2005). Profit and price effects of multispecies individual transferable quotas. Journal of Agricultural Economics, 56: $31-57$.

Hatcher, A. (2005a). Non-compliance and the quota price in an ITQ fishery. Journal of Environmental Economics and Management, 49: 427-436.

Hatcher, A. (2005b). On the microeconomics of quota management in fisheries. Marine Resource Economics, 20: 77-100.

Hatcher, A. (2012). Market power and compliance with output quotas. Resource and Energy Economics, 34: 255-269.

Hatcher, A., and D. Gordon (2005). Further investigations into the factors affecting compliance with UK fishing quotas. Land Economics, 81: 71-86. 
Herrera, G. E. (2005). Stochastic bycatch, informational asymmetry and discarding. Journal of Environmental Economics and Management, 49: 463-483.

Holland, D. (2010). Markets, pooling and insurance for managing bycatch in fisheries. Ecological Economics, 70: 121-133.

MMO (Marine Management Organisation) (2012). Catch Quota Trials 2011: Final Report. London: MMO.

Newell, R. G., J. N. Sanchirico and S. Kerr (2005). Fishing quota markets. Journal of Environmental Economics and Management, 49: 437-462.

Pascoe, S. (1997). Bycatch management and the economics of discarding. FAO Fisheries Technical Paper, 370. Rome: FAO.

Singh, R., and Q. Weninger (2009). Bioeconomies of scope and the discard problem in multiple-species fisheries. Journal of Environmental Economics and Management, 58: $72-92$.

Turner, M. A. (1997). Quota-induced discarding in heterogeneous fisheries. Journal of Environmental Economics and Management, 33: 186-195.

Vestergaard, N. (1996). Discard behaviour, highgrading and regulation: the case of the Greenland shrimp fishery. Marine Resource Economics, 11: 247-266. 
Vestergaard, N. (1999). Measures of welfare effects in multiproduct industries: the case of multispecies individual quota fisheries. Canadian Journal of Economics, 32: 729-743. 